\title{
A STUDY ON DYNEEMA FABRIC FOR SOFT BODY ARMOR
}

\author{
Ahmed Hassb Elkarem, \\ Faculty of Engineering, The University of Aberdeen, \\ Aberdeen, United Kingdom
}

\begin{abstract}
Nonwovens are highly demanded in the ballistic protection market due to their lightweight and ultra-high flexibility. This review study discusses the ballistic protection performance of a multiple nonwoven structures such as ultra-high molecular weight polyethylene, and high tenacity polyamide staple fiber. Dyneema ${ }^{\circledR}$ nonwoven fabrics provide very high energy absorption ability, greater thermal and cutting resistance compared to the other types of woven/nonwoven fabrics. In this report, a detailed overview of the numerous applications of Dyneema ${ }^{\circledR}$ nonwoven fabrics and their unique mechanical properties and types is provided. Furthermore, a detailed review of the mechanical performance and failure mechanisms is discussed in this article. The goal of this study is to provide better understanding of the uses of Dyneema ${ }^{\circledR}$ nonwoven fabrics in soft body armor which would eventually serve as a good reference for the design of lightweight, cost-effective, and protective bulletproof vests for military personnel.
\end{abstract}

\section{INTRODUCTION}

The ballistic armor materials are getting special attention by the military and civilian defense market. Different types of fibrous materials including composites [1-3] For this reason, engineers and researchers started working on new products to satisfy the essential customer's protection needs. Soft body armor is composed of fibers with high mechanical performance, light weight, and high flexibility (Fig.1). The National Institute of Justice (NIJ) defines body armor as vests designed to provide ballistic protection for the vital organs in the torso. Police, security personnel, etc., use this type of armor for protection against low velocity projectiles (NIJ levels II-A, II, and III-A) [1].
Such fibrous material consists of around 40 layers of stitched woven fibers making it bulky and heavy enough to restrict the agility of the person [4]. Since the 1970s, different companies started developing high performance fibers such as p-aramid (Kevlar®, Technora ${ }^{\circledR}$, Twaron ${ }^{\circledR}$ etc.), ultra-high molecular weight polyethylene or UHMWPE (Dyneema ${ }^{\circledR}$, Spectra ${ }^{\circledR}$ etc.), poly p-phenylene benzobisoxazole or PBO (Zyon $\left.{ }^{\circledR}\right)$, polyhydroquinone-diimidazopyridine or PIPD fibers. In general, nonwoven fabrics have been effectively utilized in multiple ballistic protection industries. This is attributed to their high flexibility, lightweight and high energy absorption capability. A study by the US Army researchers [5] showed that needle-punched nonwoven provides around $67 \%$ less structural weight than the woven fabric, while maintaining over $80 \%$ of the ballistic protection capability of the woven fabric. In nonwovens, it has been concluded by many researchers that the modulus of fibers plays the most vital role in ballistic protection.

The polyethylene nonwoven felts like Dyneema ${ }^{\circledR}$ Frag-light showed an extraordinary performance against fragments with low areal density [6]. Dyneema ${ }^{\circledR}$ fibers manufactured by DSM company, are ultra-high molecular weight polyethylene (UHMwPE) that offer maximum strength with lightest weight. This makes the number of possible applications virtually unlimited. Dyneema ${ }^{\circledR}$ fiber is produced in a patented gel spinning process in which the fibers are drawn, heated, elongated, and cooled. Stretching and spinning leads to molecular alignment, high crystallization, and low density [7]. Dyneema ${ }^{\circledR}$ has extremely long molecular chains that transfer load more effectively to the polymer backbone. Therefore, it's stronger at the same weight or lighter at the same strength than alternatives. 


\section{International Journal of Engineering Applied Sciences and Technology, 2020 Vol. 5, Issue 2, ISSN No. 2455-2143, Pages 115-118 \\ Published Online June 2020 in IJEAST (http://www.ijeast.com)}

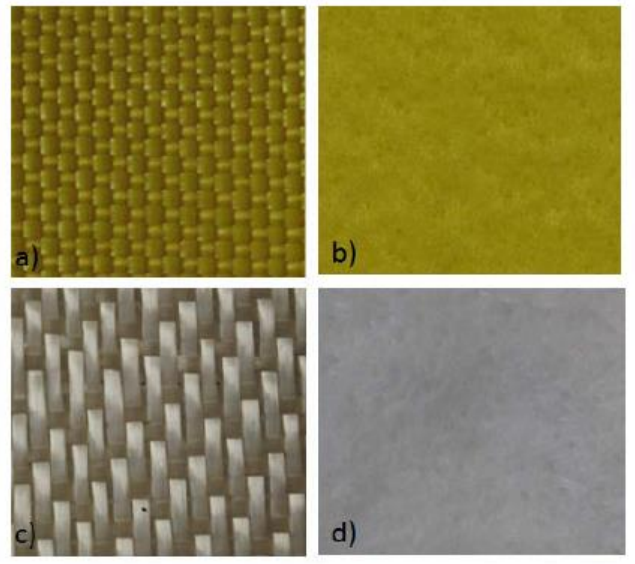

Fig.1. (a) Woven Kevlar KM2 fabric; (b) Kevlar Nonwoven; (c) Dyneema SK65 fabric; (d) SK75 Dyneema nonwoven fabric

\section{Mechanical performance of ballistic nonwovens}

The mechanical behavior of nonwovens is very different from woven materials [8-11]. The most important damage properties to notice are impact damages [12-14]. In general, nonwovens show lower strength and stiffness than woven materials, but they have significantly higher energy absorption ability and higher deformation capability. Nevertheless, the failure mechanisms of nonwovens are far more complex due to the multiple micromechanisms [11]. Fig 2 provided by Crouch et al [15], showed the relationship between specific tensile modulus and specific tensile strength of high-performance fibers.

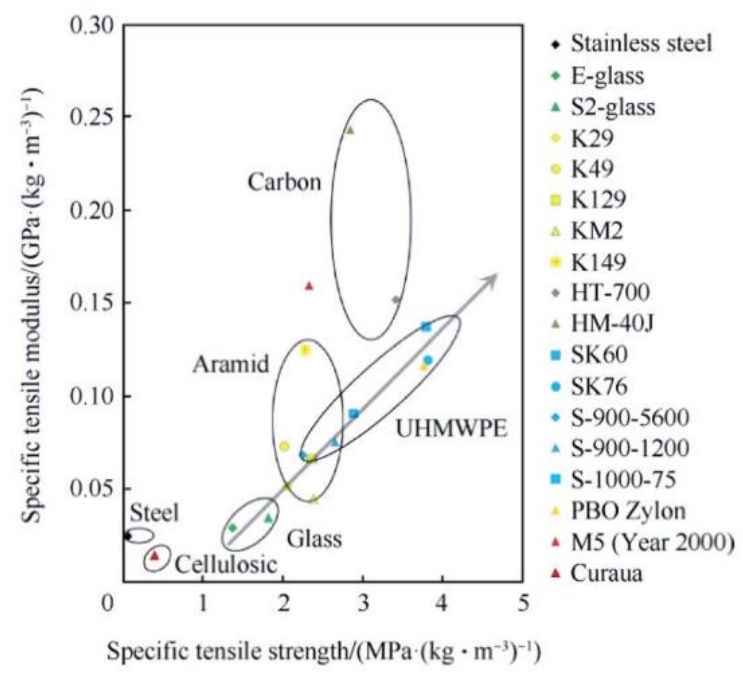

Fig 2. Relationship between specific tensile modulus and specific tensile strength of high-performance fibers (this figure has been reproduced from ref. 8 )

It was shown by Peijs et al. [16] that the low interlaminar shear strength (ILLS) obtained from a three point bending test of unidirectional composites containing UHMW-PE fibers (Table 1) is inherently due to the poor shear and compressive properties of $\mathrm{PE}$ fibers. Consequently, UHMW-PE fibers cannot be used in structural composite applications.

Table 1. Interlaminar shear strength (ILSS) of unidirectional composites; 50/50 fiber/epoxy composites.

\begin{tabular}{ll} 
Fiber & \multicolumn{1}{c}{ ILSS (MPa) } \\
UHMW-PE (untreated) & 13 \\
UHMW-PE (corona/plasma treated) & $20-30$ \\
Aramid & $45-70$ \\
E-glass & $75-95$ \\
Carbon & $80-120$
\end{tabular}

After the gel-spun fibers were produced, it became apparent that the exceptionally good shortterm mechanical properties were not matched by equally good long-term properties. In tensile tests at low strain rates, the UHMW-PE fibers exhibit a drop in Young's modulus and they exhibit a yield stress which is highly dependent on the strain rate.

In fact, it is shown that the tensile strength (yield stress) drops by at least an order of magnitude at prolonged time scales. Some representative creep data of UHMW-PE fibers, in this case of a Dyneema fiber (SK66) possessing a tensile modulus of $\sim 100 \mathrm{GPa}$.

Fig. 3 shows that initially the elongation increases proportionally to the logarithm of time [17]. Chocron et al. showed Static tensile tests were performed at different strain rates and temperatures. The static tensile tests showed that there is an important size effect: the strength of the specimens decreases when increasing the size of the specimen, for lengths of $5 \mathrm{~cm}$ or less. This effect is expected since the felt is made by mixing, combing and needle punching of $5-\mathrm{cm}-$ longfibers [6]. 


\section{International Journal of Engineering Applied Sciences and Technology, 2020 \\ Vol. 5, Issue 2, ISSN No. 2455-2143, Pages 115-118 \\ Published Online June 2020 in IJEAST (http://www.ijeast.com)}

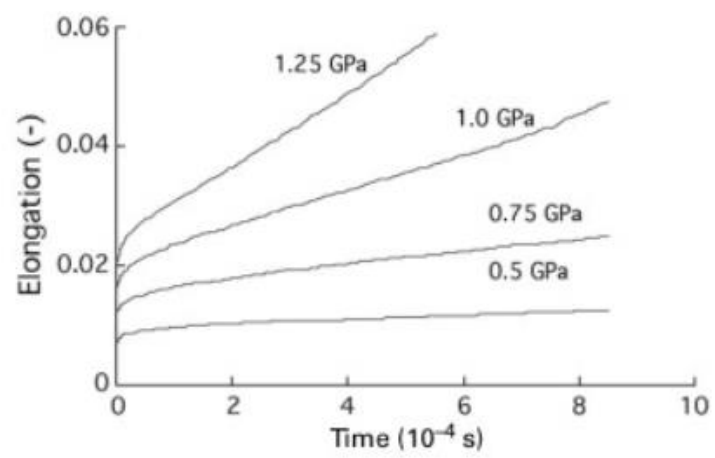

Fig. 3. Elongation (creep) of an UHMW-PE fiber at ambient temperature. The Young's modulus $(E)$ of the fiber is $\sim 100 \mathrm{GPa}$.

\section{FAILURE MECHANISMS OF BALLISTIC NONWOVEN FABRICS}

Reddy et al studied the ballistic performance of different fabrics [18]. Tensylon ${ }^{\circledR}$ material has got higher impedance over Dyneema ${ }^{\circledR}$ fabric due to its higher modulus and lack of viscous matrix. Hence, excessive delaminations are observed at the interface between the two materials. In the case of Dyneema ${ }^{\circledR}$ laminate, more attenuation of shock waves was due to the presence of viscous SIS matrix and layered structure. During the projectile penetration process laminates exhibit different failure mechanisms along the penetration path. As shown in Fig. 4. Dyneema® showed better energy absorption ability than other materials. Fig. 5. shows the damage mechanisms of Dyneema ${ }^{\circledR}$ fabric.

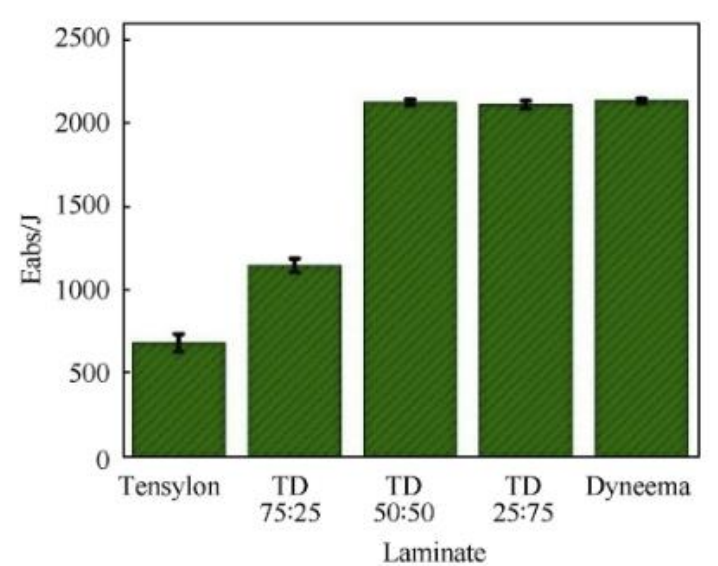

Fig. 4. Energy absorption ability

\section{CONCLUSION}

Nonwoven materials have been used in ballistic protection applications because they offer the advantages of light and flexible fabrics. This study examined the ballistic protection performance of nonwoven structure such as ultra-high molecular weight polyethylene and high tenacity polyamide staple fiber as its main component. Dyneema ${ }^{\circledR}$ nonwoven fabrics showed very high energy absorption ability, greater thermal and cutting resistance compared to the other types of woven/nonwoven fabrics. In this report, a detailed overview of the applications of Dyneema ${ }^{\circledR}$ nonwoven fabrics and their unique properties and types was provided.

Furthermore, a detailed review of the mechanical performance and failure mechanisms was shown in this article. The main goal of this report was to provide better understanding of the use of Dyneema ${ }^{\circledR}$ nonwoven fabrics in soft body armor uses which would serve as a good reference for the design of lightweight, cost-effective, and very safe vests for military personnel.
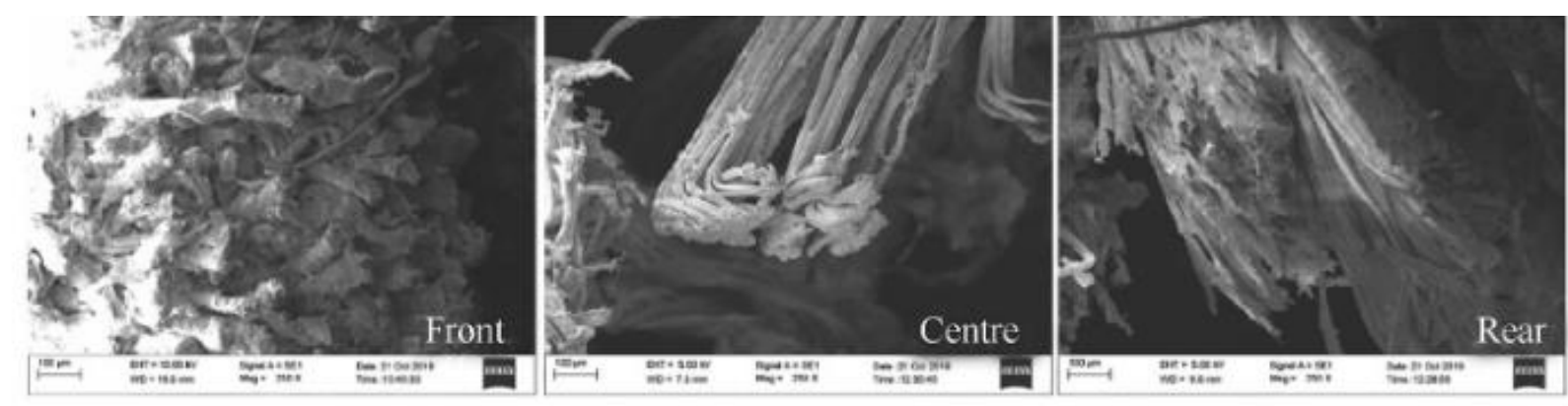

Fig. 5. Failure modes of Dyneema fibers 


\section{International Journal of Engineering Applied Sciences and Technology, 2020 Vol. 5, Issue 2, ISSN No. 2455-2143, Pages 115-118 \\ Published Online June 2020 in IJEAST (http://www.ijeast.com)}

\section{REFERENCES}

1- Elamin, M., Li, B., \& Tan, K. T. (2018). Impact damage of composite sandwich structures in arctic condition. Composite Structures, 192, 422-433.

2- Khan, M. H., Elamin, M., Li, B., \& Tan, K. T. (2018). X-ray micro-computed tomography analysis of impact damage morphology in composite sandwich structures due to cold temperature arctic condition. Journal of Composite Materials, 52(25), 3509-3522.

3- Elamin, M., Li, B., \& Tan, K. T. (2018). Impact Performance of Stitched and Unstitched Composites in Extreme Low Temperature Arctic Conditions. Journal of Dynamic Behavior of Materials, 4(3), 317327.

4- Denchev, Z., \& Dencheva, N. (2012). Manufacturing and properties of aramid reinforced composites. Synthetic PolymerPolymer Composites, 251-280.

5- Thomas, G. A. (2008). Non-woven fabrics for military applications. Military textiles, 17-48.

6- Chocron, S., Pintor, A., Gálvez, F., Roselló, C., Cendón, D., \& Sánchez-Gálvez, V. (2008). Lightweight polyethylene nonwoven felts for ballistic impact applications: Material characterization. Composites Part B: Engineering, 39(7-8), 1240-1246.

7- https://www.dsm.com/dyneema/en_GB/ourproducts/dyneema-fiber.html

8- Buet-Gautier, K., \& Boisse, P. (2001). Experimental analysis and modeling of biaxial mechanical behavior of woven composite reinforcements. Experimental mechanics, 41(3), 260-269.

9- Durville, D. (2005). Numerical simulation of entangled materials mechanical properties. Journal of materials science, 40(22), 5941-5948.

10- Boisse, P., Gasser, A., Hagege, B., \& Billoet, J. L. (2005). Analysis of the mechanical behavior of woven fibrous material using virtual tests at the unit cell level. Journal of materials science, 40(22), 5955-5962.

11- Ridruejo, A., González, C., \& LLorca, J. (2012). A constitutive model for the in-plane mechanical behavior of nonwoven fabrics. International Journal of Solids and Structures, 49(17), 2215-2229.

12- TAN, K., ELAMIN, M., \& LI, B. (2017). Impact Performance and Damage Behavior of Composite Sandwich Structures in Arctic Condition. In Proceedings of the American Society for Composites-Thirty-second Technical Conference.

13- Elamin, M., \& Varga, J. (2020). Plate impact method for shock physics testing. Material Sci \& Eng, 4(1), 31-35.

14- Mohammed, M. (2018). IMPACT AND POST IMPACT RESPONSE OF COMPOSITE SANDWICH STRUCTURES IN ARCTIC CONDITION . (Electronic Thesis or Dissertation). Retrieved from https://etd.ohiolink.edu/

15- G. Crouch, Body armour - New materials, new systems, Def. Technol., 2019, 15(3), 241-253.

16- Peijs, T., Rijsdijk, H. A., De Kok, J. M. M., \& Lemstra, P. J. (1994). The role of interface and fibre anisotropy in controlling the performance of polyethylene-fibrereinforced composites. Composites science and technology, 52(3), 449-466.

17- Lemstra, P. J., \& Rastogi, S. (2001). Processing flexible polymers to high performance fibers. The encyclopedia of materials: science and technology, 78777883.

18- Reddy, T. S., Reddy, P. R. S., \& Madhu, V. (2017). Response of E-glass/epoxy and Dyneema ${ }^{\circledR}$ composite laminates subjected to low and high velocity impact. Procedia engineering, 173, 278-285. 